\title{
SERO-PREVALENCE OF COMMON BOVINE RESPIRATORY VIRAL DISEASES IN SAUDI ARABIA
}

\author{
MOHAMMED ALI AL-HAMMADI ${ }^{*}$ and MAGED GOMAA HEMIDA ${ }^{(*, * *)}$ \\ *Department of Microbiology and Parasitology, College of Veterinary Medicine, King Faisal; University, Saudi Arabia. \\ *** Department of Virology, Faculty of Veterinary Medicine, Kafr El-Sheikh University, Egypt. \\ Email: gomaa55@gmail.com
}

\section{ABSTRACT}

Received at: 19/12/2013

Respiratory viral diseases in cattle are an important cause of mortality especially in young calves. Of this group of viruses, present study chooses to focus on Infectious Bovine Rhinotracheitis virus (IBR), Bovine viral diarrhea (BVD), Bovine Parainfluenza-3 (BPI-3), Respiratory syncytial virus (RSV), and Bovine Adenoviruses (BAdVs). Little is known about the prevalence of these viruses throughout the Gulf and so the primary goal of the study was to test the exposure history of different cattle herds in Saudi Arabia to the indicated viruses. To achieve Accepted: 11/1/2014 this goal, 359 serum samples were collected from four regions in Saudi Arabia (Eastern, Central, Northern, and Western regions). Commercially available ELISA kits were used on these samples. The results showed the high seroprevalence of the indicated viruses in Saudi Arabia. The seroprevalence of IBR, BVD, RSV, PI-3 and BAdV-3 were $50 \%, 35 \%, 30 \%, 39 \%$ and $49 \%$ respectively. To the best of our knowledge this is the first study to report the high seroprevalence of BVAdV-3 in the Gulf region, or especially in Saudi Arabia. Since the animals used in the current study have not been vaccinated against the indicated viruses, it is assumed that those herds were exposed to these viruses previously, and thus seroconverted to against these viruses. Further molecular studies are needed to examine these viruses, and the application of science- based vaccination programs is highly recommended to protect these animals from the indicated pathogens.

Keywords: Respiratory virus, seroprevelance, $B H V-1, R S V, B V D, B P I-3, B A d V-3$

\section{INTRODUCTION}

Bovine respiratory disease (BRD) is a major health problem for cattle worldwide, and research on the area has long been priority. In economic terms, BRD leads to decreased productivity due to, high levels of mortality and morbidity, increased veterinary and labor costs and reduced carcass value. The causation is multifactorial and the disease appears to be a result of the interaction of infectious micro-organisms and such predisposing factors as host defense, environment and stress. Viruses and bacteria in combination with stress play a key role in triggering acute respiratory infections. It is generally accepted that viruses are the first pathogens to play a role in infecting animals, whereas bacteria act as second invaders to worsen the ill animal's condition (Solis-Calderon et al., 2007). Several viruses such as bovine respiratory syncytial virus (BRSV), bovine parainfluenza type 3 (BPI3), bovine herpesvirus-1 (BoHV-1), bovine viral diarrhea virus (BVD) and bovine Adenoviruses (BAdVs) are detected in clinical cases (Ellis, 2001). While usually considered a respiratory pathogen, infection with BoHV-1 can also cause abortion in pregnant cattle. These agents may represent risks to camels, other livestock and even human population (Teshome et al., 2003). Infection with these viruses can also facilitate invasion of opportunistic secondary pathogens such as Mannheimia haemolytica, Pasteurella multocida, Haemophilus somnus and a number of mycoplasma species such as M. bovis and M. dispar (Hodgson et al., 2005). Infectious bovine rhinotracheitis, caused by BoHV-1, is a disease of domestic and wild cattle. BoHV-1 is a member of the genus Varicellovirus in the subfamily Alphaherpesvirinae, which belongs to the Herpesviridae family (Nandi et al., 2009). The BoHV causes respiratory disease, abortion, conjunctivitis, and other clinical forms of disease complex. Genetic analyses of various clinical isolates have found at least three distinct BHV-1 subtypes; a respiratory subtype, a genital subtype, and an encephalitic subtype designated as BoHV-1.1, BoHV1.2, and BoHV-1.3, respectively (Fuchs et al., 1999).

BVDV is classified in the virus family Flaviviridae and is a member of the genus Pestivirus. This virus is detected in most clinical cases that are investigated early after the onset of clinical signs (Lanyon et al., 2013). On farms where BVDV is not well controlled, 
this can lead to immunosuppression and influence the progression of BRD.

BPI-3V is in the genus Respirovirus of the subfamily Paramyxovirinae, order Mononegavirales, of the family Paramyxoviridae (Ellis, 2010). This virus causes clinical symptoms in the respiratory system of cattle and sheep. Antibodies of BPI-3V have been found in humans, cow, sheep, and other animals. Like BoHV-1, BPI-3V is a viral agent of shipping fever. The highly conserved partial matrix (M) protein has been used recently for the rapid identification of PI-3 in feedlot cattle (Horwood et al., 2008).

Bovine adenoviruses (BAdVs) belong to the family Adenoviridea, and. appear to be related to other diseases. and $\mathrm{BAV}-3$ is related to respiratory infections of cattle (Castano and Eisenbarth, 1990). BAdVs are a group of viruses which cause various symptoms in cattle including pneumonia, conjunctivitis, diarrhea and polyarteritis (Castano and Eisenbarth, 1990). Based on their serological and biological criteria, BAdVs can be classified in two groups, the first belongs to the Mastadenovirus genera including BAdVs (Hodgson et al., 2005; Horwood et al., 2008) while the other group belongs to genus Atadenovirus including BAdVs (Zhu et al., 2011). BAdV-3 is one of the most important causes of respiratory manifestations in cattle especially newborn calves (Zhu et al., 2011).

An episode of BRD, can cause permanent lung damage, making animals more susceptible to subsequent episodes of respiratory disease compromising growth rates and economic returns for the farmer (Thonur et al., 2012). Few reports are available on the respiratory diseases of farm animals in Saudi Arabia (Barbour et al., 1997). Main goal in this current study was to test the exposure history of cattle population in several regions in KSA to the indicated major respiratory viruses.

\section{MATERIALS and METHODS}

\section{Sampling}

Serum samples used in the current study were originally collected to perform a serosurveillance of Rift Valley Fever virus in Saudi Arabia (Al-Afaleq et al., 2012). A random sample of of 359 bovine serum samples was collected randomly from four different regions (Table 1). Serum samples were collected by venipuncture from the jugular vein, left overnight at $4^{\circ} \mathrm{C}$. Serum samples were then processed by centrifugation at $5000 \mathrm{rpm}$ for $10 \mathrm{~min}$. Serum samples were heat inactivated at $56^{\circ} \mathrm{C}$ for $30 \mathrm{~min}$ then stored at $-80^{\circ} \mathrm{C}$ till tested.

\section{Enzyme linked immunosorbant assay (ELISA)}

Testing of the bovine sera was conducted using the commercial available, RESPIRATORY ELISA PENTAKIT $^{\circledR}$ (BIO K 028/5 from Bio-X Diagnostics, Belgium) used in accordance with the manufacturer's instructions. ELISA plates were coated with monoclonal antibodies and inactivated viruses. Tested sera were diluted at a ratio of 1:500 in the dilution buffer. Samples were added to the corresponding wells, incubated at $37^{\circ} \mathrm{C}$ for $1 \mathrm{hr}$. Plates then washed three times with the washing buffer. The conjugate was diluted 1:50 in 1X dilution buffer and added to each wells. Plates were then lidded, incubated at room temperature for one hour, and washed as stated above. Undiluted chromogen was added to each well; plates were then incubated in dark at room temperature for 10 minutes. The reaction was stopped by adding $50 \mu \mathrm{l}$ per well of the undiluted stop solution followed by reading Optical Density (OD) at $450 \mathrm{~nm}$.

\section{Interpretation of test results}

Net OD was calculated by subtracting the OD value of the negative control column (no. 6) from corresponding values of columns $1,2,3,4$ and 5 . Net OD of the positive serum control must exceed the following threshold for the test to be acceptable: BHV-1 > 0.700; $\mathrm{BVD}>1.000$; $\mathrm{BRSV}>0.800$; $\mathrm{BPI} 3$ $>0.800 ; \mathrm{BAd}-\mathrm{V}-3>0.600$. If the plate passed internal quality control criteria, sample positivity was calculated using the following equation:-

Percentage Positivity $(P P)=\frac{\text { Sample Serum Net OD }}{\text { Positive Serum Net OD }} * 100$

Samples were considered positive if PP exceeded $30 \%$ for $\mathrm{BHV}-1,20 \%$ for BVD, BRSV, BPI3; and $10 \%$ for BAdV-3 as indicated by the kits instructions.

\section{Statistical analysis}

\section{RESULTS}

\section{Seroprevalence of BHV-1 in KSA}

According to recorded results high seroprevalence of BHV-1 among cattle was reported in the Western and Eastern regions (64 and $53 \%$ ) respectively. The lowest seroprevalence was reported in the central areas (5\%). However, central regions Riyadh was showing moderate seroprevalence (6\%) (Figure 1). In total, the overall seroprevalence in the five tested areas was as high as 50\% (Figure 1 and Table 2). 


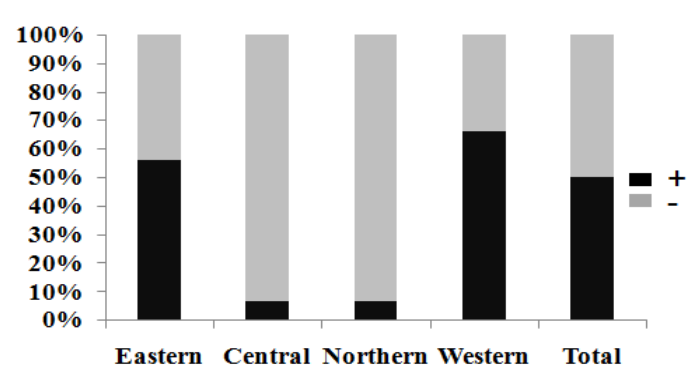

Fig. 1: Seroprevalence of IBR in KSA

\section{Seroprevalence of BVD in KSA}

The highest reported rates of seropositivity was found in the Western region (50\%), followed by the Eastern region (38\%). Both the central and Northern areas showed (8\% and 1\%) positive results respectively. The overall seroprevalence of BVD across regions was 35\% (Figure 2 and Table 2).

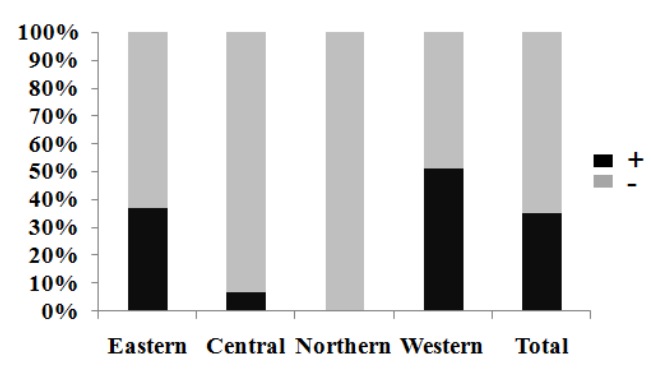

Fig. 2: Seroprevalence of BVD in KSA

\section{Seroprevalence of RSV in KSA}

The lowest seroprevalence for BPI-3 virus was reported among herds in the central region (1\%). The other regions including the Eastern, Northern and the Western were showing positive rates as of 33\%, 12\%, and $40 \%$ respectively. The overall prevalence of PI-3 among the tested samples was 38\%.

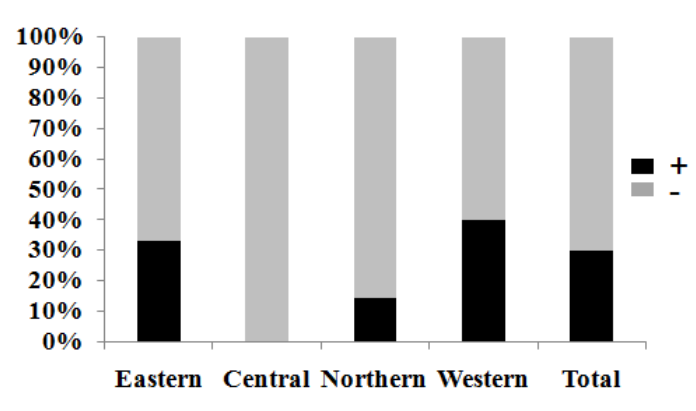

Fig. 3: Seroprevalence of RSV in KSA

\section{Seroprevalence of BPI-3 in KSA}

The highest seroprevalence of BPI-3 was reported among samples collected from the Western region (70\%) while, the lowest seroprevalence was reported in the cattle flocks of the Northern region. Meanwhile, the Eastern and central regions showed seroprevalence of (30\% and 6\%) respectively.

The obtained results are showing high seroprevalence among animals in the Western areas with (70\%) followed by $30 \%$ at the Eastern region while the central and Northern regions were showing $10 \%$ and $6 \%$ respectively (Figure 4). The overall prevalence of BPI-3 in KSA was 39\% (Figure 4 and Table 2). 


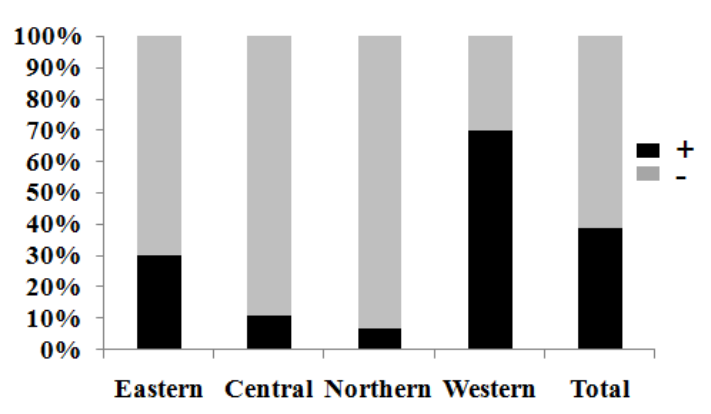

Fig. 4: Seroprevalence of PI-3 in KSA

\section{Seroprevalence of BAdV-3 in KS}

The highest seroprevalence reported among all cattle flocks against BAdV-3 was reported in the cattle flocks of the Western region. The second most affected region was the Northern region as $(50 \%)$ of the tested animals were seropositive for BAdV-3. The Eastern and Central regions were had variable results (22\% and 29\%) respectively (Figure 5). The overall seroprevalence of BAdV-3 in all tested animals was 49\% (Figure 5 and Table 2).

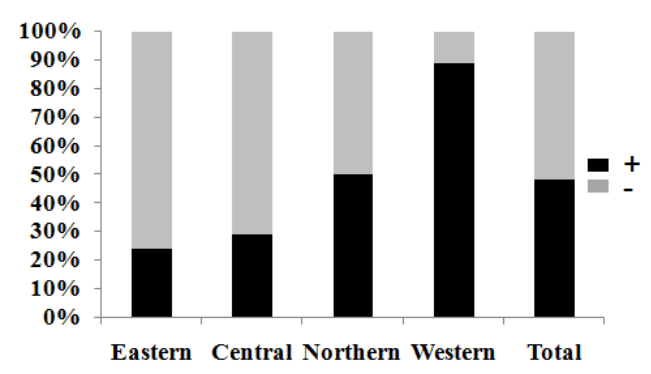

Fig. 5: Seroprevalence of BAdV-3 in KSA

Summary of the seroprevalence of common respiratory viruses among cattle flocks in different regions of Saudi Arabia

Table 2 summaries the seroprevalence of common respiratory viruses in adult cattle in several regions in Saudi Arabia. In general, almost most animals included in the current study were seroconvert to different viruses. The overall seroprevalence of different regions were $(50 \%, 35 \%, 30 \%, 39 \%$ and $49 \%)$ in the following regions (Eastern, Central, Northern, Western and Western) respectively.

Identification of the animals reactive to several viruses

Among the interesting results of the current study was the identification of animals showed high seroprevalence of two or more viruses. Table 3 summarizes the reactive animals to two or more viruses in different locations within Saudi Arabia.

Table 1: Number of the serum samples collected from each region within Saudi Arabia.

\begin{tabular}{cccccc}
\hline Region & Eastern & Central & Northern & Western & Total \\
\hline No. of samples & 94 & 92 & 84 & 89 & 359 \\
\hline
\end{tabular}

Table 2: Summary of the seroprevalence of common respiratory viruses among cattle flocks in different regions of Saudi Arabia.

\begin{tabular}{cccccc}
\hline Region & Eastern & Central & Northern & Western & Total \\
\hline BHV-1 & 53 & 5 & 6 & 64 & 50 \\
\hline BVD & 38 & 8 & 1 & 50 & 35 \\
\hline BRSV & 33 & 1 & 12 & 40 & 30 \\
\hline BPI-3 & 30 & 10 & 6 & 70 & 39 \\
\hline BAdV-3 & 22 & 29 & 50 & 90 & 49 \\
\hline
\end{tabular}


Table 3: Percentages of the animals reactive to several viruses.

\begin{tabular}{|c|c|c|c|c|c|}
\hline Region & A & B & C & D & $\mathbf{E}$ \\
\hline Eastern & 25 & 24 & 11 & 7 & 11 \\
\hline Central & 22 & 30 & 9 & 10 & 13 \\
\hline Northern & 32 & 29 & 30 & 27 & 26 \\
\hline Western & 11 & 18 & 30 & 12 & 9 \\
\hline $\begin{array}{l}\text { A- Animals } \\
\text { B- Animals } \\
\text { C- Animals } \\
\text { D- Animals } \\
\text { E- Animals }\end{array}$ & $\begin{array}{l}3 \mathrm{HV}- \\
\text { AdV- } \\
3 \mathrm{HV} \\
3 \mathrm{VD} \\
3 \mathrm{HV}\end{array}$ & $\begin{array}{l}\mathrm{V} \\
\mathrm{V}+ \\
\mathrm{V}+1\end{array}$ & & & \\
\hline
\end{tabular}

\section{DISCUSSION}

Bovine respiratory viruses are among the most common causes of high morbidity and mortality in bovine species worldwide (Yesilbag and Gungor, 2008). They cause major economic losses to the dairy industry due to the sharp reduction in milk and meat production (Potgieter, 1997). This is in addition to the high mortality rates especially among the young calves (Yesilbag and Gungor, 2008). This study was designed to investigate the immune status of the most common respiratory viruses affecting cattle (BHV-1, BVD, BPI-3, RSV, and BAdV-3). Samples in the current study were collected from small flocks of 4 different regions in Saudi Arabia. Those animals were non-vaccinated against the indicated viruses. Our results are showing moderate level of exposure to several viruses such as IBR and BAdV-3 (50\% and $49 \%)$ respectively. This is in contrast to another study had been done in Uruguay as $37 \%$ of the tested animals were seropositive to IBR (Guarino et al., 2008). Similar serosurveillance studies had been conducted in many countries in the world and showing variable Seroprevalence among the tested cattle flocks. These studies included Yuctan (14\%), Spain (21\%), and Mexico (14\%) (Mainar-Jaime et al., 2001; Solis-Calderon et al., 2007). Our data is very much closer to the previous records for many viruses especially BVDV (Table 2 and Figure 2). Similar studies had also been conducted in USA to detect the Seroprevalence of BHV-1, BRSV, and BVD in American bulls. These studies showed higher seroprevalence of the indicated viruses than our results. For example, the incidence of IBR was up to 92\% among the tested animals (Sausker and Dyer, 2002). Interestingly enough, some viruses such as BVDV and BRSV were almost negative in some areas such as Northern and Central regions respectively. This is in contrast to high seroprevalence of BAdV-3 in the Western region (90\%), (Table 2 and Figure 5). It is worthwhile to report that the current study is the first study to investigate the seroprevalence of BAdV-3 in Saudi Arabia. Interestingly enough, we identified animals exposed to two or several viruses at the same time as shown in (Table 3). It was found that the highest seroprevalence of two or more viruses was recorded in the Northern region of Saudi Arabia. One possible explanation for is that the area is relatively cold throughout the year. This cold weather may favor the spreading of respiratory viruses. This is consistent with other research that reported high prevalence of winter dysentery among calves during cold winter weather (Park et al., 2007). High seroprevalence of major respiratory viruses was reported in several regions in Saudi Arabia. The authors strongly suggest that study to evaluate the present situation of these viruses and perform intensive vaccination programs against the indicated viruses.

\section{ACKNOWLEDGMENT}

This work has been funded by a grant (Grant no130248) from the deanship of Research at King Faisal University, Saudi Arabia. Thanks are also directed to Mr. Anwar Al-Kubati for his technical laboratory assistance.

\section{CONCLUSIONS}

High seroprevalence of the common respiratory viruses of cattle including BHV-1, BVD, RSV, BPI-3 and BAdV-3 in 4 geographic locations in Saudi Arabia was reported by the current study. Since those animals were non-vaccinated against the indicated viruses, this indicates the exposure of the tested animals to these viruses at certain point.

\section{REFERENCES}

AL-Afaleq, A.I.; Hussein, M.F.; AL-Naeem, A.A.; Housawi, F. and Kabati, A.G. (2012): Seroepidemiological study of Rift Valley fever (RVF) in animals in Saudi Arabia. Trop Anim. Health Prod., 44, 1535-9.

Barbour, E.K.; Nabbut, N.H.; Hamadeh, S.K. and AL-Nakhli, H.M. (1997): Bacterial identity and characteristics in healthy and unhealthy respiratory tracts of sheep and calves. Vet. Res. Commun, 21, 421-30.

Castano, L. and Eisenbarth, G.S. (1990): Type-I diabetes: a chronic autoimmune disease of human, mouse, and rat. Annu Rev Immunol, 8, 647-79. 
Ellis, J.A. (2001): The immunology of the bovine respiratory disease complex. Vet. Clin. North. Am. Food Anim. Pract., 17, 535-50, vi-vii.

ELLIS, J.A. (2010): Bovine parainfluenza-3 virus. Vet. Clin. North Am. Food Anim. Pract, 26, 575-93.

Fuchs, M.; Hubert, P.; Detterer, J. and Rziha, H.J. (1999): Detection of bovine herpesvirus type 1 in blood from naturally infected cattle by using a sensitive PCR that discriminates between wild-type virus and virus lacking glycoprotein E. J. Clin. Microbiol., 37, 2498-507.

Guarino, H.; Nunez, A.; Repiso, M.V.; Gil, A. and Dargatz, D.A. (2008): Prevalence of serum antibodies to bovine herpesvirus-1 and bovine viral diarrhea virus in beef cattle in Uruguay. Prev. Vet. Med., 85, 34-40.

Hodgson, P.D.; Aich, P.; Manuja, A.; Hokamp, K.; Roche, F.M.; Brinkman, F.S.; Potter, A.; Babiuk, L.A. and Griebel, P.J. (2005): Effect of stress on viral-bacterial synergy in bovine respiratory disease: novel mechanisms to regulate inflammation. Comp Funct Genomics, 6, 244-50.

Horwood, P.F.; Gravel, J.L. and Mahony, T.J. (2008): Identification of two distinct bovine parainfluenza virus type 3 genotypes. J Gen Virol, 89, 1643-8.

Lanyon, S.R.; Hill, F.I.; Reichel, M.P. and Brownlie, J. (2013): Bovine viral diarrhoea: Pathogenesis and diagnosis. Vet $\mathrm{J}$.

Mainar-Jaime, R.C.; Berzal-Herranz, B.; Arias, P. and Rojo-Vazquez, F.A. (2001): Epidemiological pattern and risk factors associated with bovine viral-diarrhoea virus (BVDV) infection in a non-vaccinated dairycattle population from the Asturias region of Spain. Prev Vet Med, 52, 63-73.

Nandi, S.; Kumar, M.; Manohar, M. and Chauhan, R.S. (2009): Bovine herpes virus infections in cattle. Anim Health Res Rev, 10, 85-98.
Park, S.J.; Kim, G.Y.; Choy, H.E.; Hong, Y.J.; Saif, L. J.; Jeong, J.H.; Park, S.I.; Kim, H.H.; Kim, S.K.; Shin, S.S.; Kang, M.I. and Cho, K.O. (2007): Dual enteric and respiratory tropisms of winter dysentery bovine coronavirus in calves. Arch Virol, 152, 1885-900.

Potgieter, L.N. (1997): Bovine respiratory tract disease caused by bovine viral diarrhea virus. Vet Clin North Am Food Anim Pract, 13, 471-81.

Sausker, E.A. and Dyer, N.W. (2002): Seroprevalence of OHV-2, BVDV, BHV-1, and BRSV in ranch-raised bison (Bison bison). J. Vet. Diagn Invest, 14, 68-70.

Solis-Calderon, J.J.; Segura-Correa, J.C.; AguilarRomero, F. and Segura-Correa, V.M. (2007): Detection of antibodies and risk factors for infection with bovine respiratory syncytial virus and parainfluenza virus-3 in beef cattle of Yucatan, Mexico. Prev. Vet. Med., 82, 102-10.

Teshome, H.; Molla, B. and Tibbo, M. (2003): A seroprevalence study of camel brucellosis in three camel-rearing regions of Ethiopia. Trop Anim Health Prod, 35, 381-90.

Thonur, L.; Maley, M.; Gilray, J.; Crook, T.; Laming, E.; Turnbull, D.; Nath, M. and Willoughby, K. (2012): One-step multiplex real time RT-PCR for the detection of bovine respiratory syncytial virus, bovine herpesvirus 1 and bovine parainfluenza virus 3. BMC Vet. Res., $8,37$.

Yesilbag, K. and Gungor, B. (2008): Seroprevalence of bovine respiratory viruses in NorthWestern Turkey. Trop Anim Health Prod, 40, 55-60.

Zhu, Y.M.; YU, Z.; CAI, H.; GAO, Y.R.; DONG, X.M.; LI, Z.L.; SHI, H.F.; MENG, Q.F.; LU, $C$. and XUE, F. (2011): Isolation, identification, and complete genome sequence of a bovine adenovirus type 3 from cattle in China. Virol J., 8, 557.

\section{مسوحات سيرولوجية على بعض الأمراض الفيروسية التى تصيب الجهاز التنفسى للأبقار فى المملكة العربية السعودية

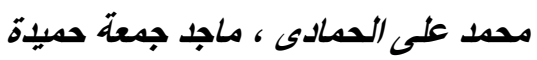 \\ Email: gomaa55@gmail.com}

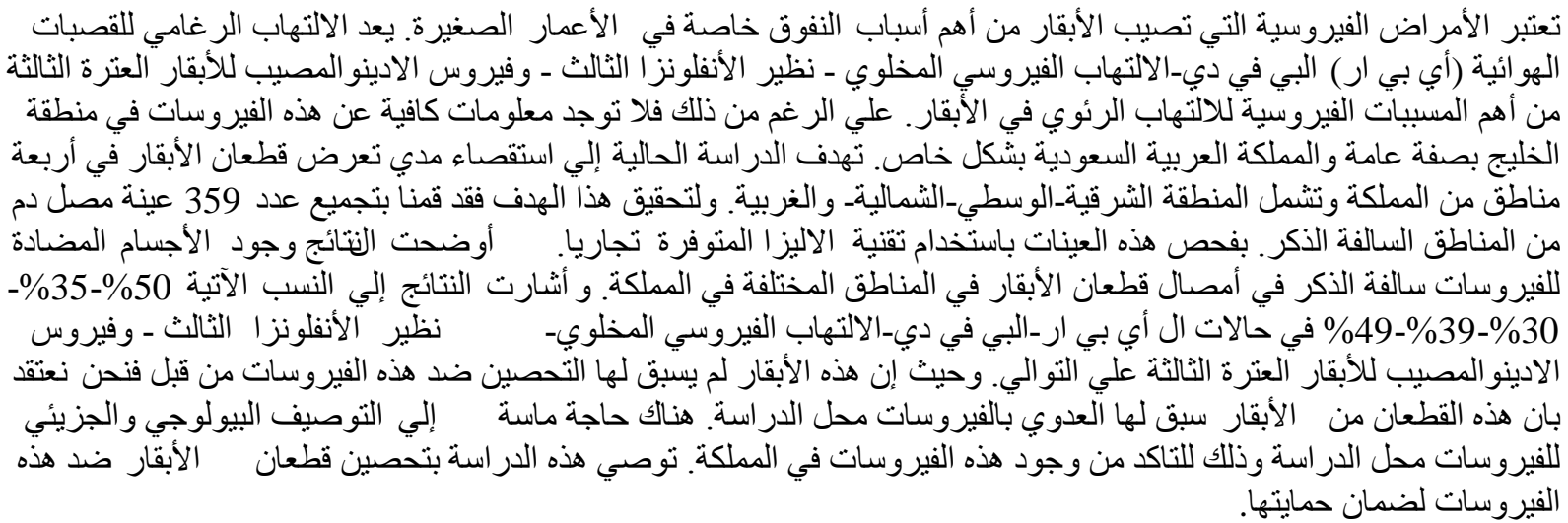

